\title{
The Application of Green Plants in the Interior Space
}

\author{
Jing Zeng, Canwen Li
}

College of Forestry, Sichuan Agricultural University, Wenjiang, 611130

Keywords: Green plants, Interior space, environment

\begin{abstract}
With the development of the society, the progress of The Times, constantly improve the people's standard of living, people in the pursuit of quality of life also had a higher. But is also due to the development of the society, people's living environment and living space has been a great deal of pollution, people are enjoying prosperous and bustling city, rich material life at the same time, also because of pollution and the deterioration of the noise, and has infinite linger on the old natural landscape. For nearly 30 years, the application of indoor plants developed rapidly and technical progress makes more kinds of the survival of plants indoors, people more and more realized the plant to reduce pollution, improve environment and so on, thus the plants sprouted a strong interest in again. As people on the environment is beautiful and the physical and mental health have a more profound understanding and awareness, green plant, nature has become the public for interior decoration, the most favored of the "products"; Now, put the plant element into the interior design and fashion has become a new demand, is also the future development direction of interior design.
\end{abstract}

\section{The important role of green plants in the interior space}

To the introduction of the green plant is not only for indoor decoration, but also as to improve the environmental quality, meet people's physiological needs one of the indispensable factors ${ }^{[1]}$. Plant itself has many physiological functions, plant life activities in the process of evaporation and cooling can adjust the indoor temperature. Heatabsorption ofheatfrom the air during the day and night, thus to reduce the temperature difference between day and night, effective regulation of indoor air temperature. Plants through cultivation matrix of evaporation and transpiration, be able to release the moisture in the air, thereby increasing indoor humidity, become a humidifier indoor. All along, the plant has the laudatory title of "natural" oxygen generator, it can absorb carbon dioxide during photosynthesis, making oxygen, improve indoor air quality. Some plants also have very strong ability. Aloe, banana, spider, for example, grass of insulation foam and formaldehyde pollution; Aloe vera, bracketplant can eliminate formaldehyde pollution; Ivy can remove the office released from cigarettes, synthetic fiber and plastic of benzene; Flowers and plants such as Chinese rose, rose, can absorb more hydrogen sulfide, benzene, phenol, the harmful gas such as hydrogen fluoride, ether; Set, such as curvature of leaf blade large foliage plants and flowers, can absorb more than $80 \%$ of a variety of harmful gas ${ }^{[2]}$. Because of, in plant leaf is more directional sound coming from one direction have divergent effect, so the plant also can have the effect of noise cancellation.

Indoor plants can be used to form or adjust the space, can not only keep all parts of its function, and do not break the open sex of integral space and integrity. Such as between dining-room and sitting room wants to have an independent small space, besides partition to separate, also can use green plants in space. When put some big leaf green plants on angular wall or beside the sofa, can make these blunt object becomes downy, changed the original layout of the contour line, make the angular geometric shapes in the interior space is full of diffusion and angry, the appropriate plant 
layout, is a good way to reconcile interior space layout to indoor soft emotional appeal, make interior space more kind, this is any decoration material can't replace.

People's perceptions of the various natural landscape brought to people's different in the mind, physical body effect. Through the appreciation of landscape, thus the viewer's brain to form a kind of exciting signal, feel pleasant, relaxed and happy, to achieve the aesthetic artistic conception of landscape appreciation, invigoration is beneficial to build ${ }^{[3]}$. In recent years, clinical psychology, environmental psychology, sociology, behavioral science disciplines such as researchers are working on the benefits of human contact with plants, urban people spend most of my time in the office, laboratory and other indoor places. Isolation isolated environment make the person produces negative effect, make the person has a sense of deprivation. For good indoor, profusion colorful plants and nature's sunshine can reduce stress, refreshing, and make the person produces healthy mood. Introducing green plants indoors, can strengthen the psychological link between man and nature, make people don't think surrounded in the interior space is tired of, don't feel like outdoor due to loss of sheltered insecurity, thus increasing people indoors and in a comfortable feeling and comfortable feeling.

\section{Household green plant space design approach}

Display is the most common indoor plant landscape and the most common arrangement, usually have a dot, line type, type, three of which point is the most common, the potted plants on the desktop, tea table, foot, windowsill and the corner, a green view ${ }^{[4]}$. If the potted plant is put into a line or organized into freestyle, rules, the show line type and type of arrangement, can have the effect of organization interior space, if combined with furniture at the same time, it can also play a space effect for space. Using display afforest adornment, the main display should be considered whether the ways, methods and instruments used in accordance with the requirements of the decoration.

Halls and restaurants, such as indoor areas need to split, with belt clings to plant quarantine, or the fence with a bar or design decorative pattern to provide clings to plants and clings to coordinate in shape, color, material, etc. In order to make reasonable interior space division, coordination, and beautiful and practical.

Indoor wall greening design, also be the welcome of people. The main form of wall-mounted have hang wall hanging, hanging wall managed to put, recessed method and window method. Can advance in the wall set up local uneven hole wall and wall, for placed potted plants; Can also be placed against the wall ground flowerpot, or planting groove, build by laying bricks or stones and then grows on plants, make its growth along the wall, form indoor local green space; Or on the wall to set up support, in the case of do not take up the place flowerpot, to enrich the space. Using this method of decoration, mainly considering plant posture and color. Trailer clings to plant material in the most commonly used, and other types of plant material are also commonly used.

Within the larger space indoors, combined with the ceiling, lamps and lanterns. Put it beside the window, the corner, the furniture has a certain volume of Yin hanging plants, can improve indoor artificial buildings as dry as a chip and drab feeling caused by the hard line, build a lively space stereo aesthetic feeling, and accounts for "days don't cover", can make full use of space ${ }^{[4]}$. This kind of adornment to use a metal or plastic hanging POTS, with the organic knot of material distribution, in order to obtain unexpected adornment effect.

Plant type is more commonly used for indoor garden, and a large hall which has sufficient space, plant using natural type, more dependent accumulation and dispersion, density, pay attention to posture and the harmonious collocation of color, also should pay attention to use the color of foliage 
plants to enrich the landscape picture, at the same time also can match with rocks, waterscape to form indoor mini garden, simulating the nature landscape, give a person to return to the beauty of nature.

\section{Concrete Interior Space Green Plants into Discussion}

Most function of the sitting room is house home a place, is not only the main daily life place, it is the center of the family activities, also is the main place of reception guests, it is a very important activity space, so it is the focus of afforest adornment. To afforest adornment should pay attention to consider the sitting room living room the limitation of custom, but also want to reflect gracious hospitality, happy cheerful mood. Generally in the medium and small potted plant or flower arrangement way, avoid into large potted, avoid the attract mosquitoes and stressful; Also can choose bigger blades, the plant is tall Malabar millet, Brazil, the incredible hulk, iron and other plants or lianas, such as Chrysalidocarpus lutescens, Epipremnum aureum, devil's ivy, turquoise as the main feature, such as full-service business; Optional also choose stump potted landscape as the main feature, elegant simplicity. In the sitting room had better not place needles plants and the cuckoo. No matter in what plants as the main feature, in a few cases, flower is worn, near the window frame of sofa tea table and other places all need a small basin of small and exquisite, deserve to go up colorful foliage plants, such as the peacock arrowroot, calla, etc., this combination can highlight the layout of the sitting room the theme, make indoor bright again at the same time, but remember, the number of plant shouldnot be too much of the sitting room, can appear otherwise the sitting room is messy.

Restaurant is a place for family or guests dining or party, is a place where people will go to every day, decoration should be elegant, clean as the theme, can put color lively appropriately indoor foliage plants. In the center of the table you can configure some elegant flower arranging, but wants to be coordinated with mensal photograph in terms of color and size, plants also should not be too multifarious. In adornment restaurant, want to consider to save area, points with stereo adornment is given priority to, in principle is the selected plant type. For instance in a multi-tiered flower on display a few small and exquisite, green indoor foliage plants (such as douban green, grass, asparagus, cold water lily flowers, such as the peacock arrowroot); Can also be in the dining room wall decoration indoor foliage plants such as devil's ivy, Malabar millet, the Netherlands, iron, etc., to the restaurant to create a harmonious, lively atmosphere, enhance the appetite of people.

The bedroom is people rests, sleep, about a third of the time in one's life is spent in sleep, so the afforest adornment of the bedroom should be around the rest function, through the plant decoration, give people build a can relieve nerves, relieve fatigue, ease and the atmosphere of the photographer. In the bedroom, because the furniture is more, narrow space, on the choice of plants to give priority to with small, pale green, try to be fewer but better, it helps to sleep; A relatively quiet for the character, put in the bedroom foliage plants, plant posture to light and thin, such as orchidAsparagus fern and so on; For the personality extrovert, the bedroom besides foliage plants, can also be appropriate to add some colorful sowbread potted flower, etc. If space permits, also can decorate in the bedroom corner cycas in Brazil, the window put jasmine or Chinese rose, or choose the orchids, daffodils and other fresh scent and plants can absorb carbon dioxide in the night, is helpful for people to sleep. But should pay attention to some fragrance thick plants cannot be put in the bedroom, in order to avoid the smell them cause dizziness, poisoning, etc.

As a place for reading, learning, the study should have a kind pure and fresh, quiet, elegant atmosphere, to help people learn attentively, reduce fatigue, increase interest. So on the choice of plants should be concise and easy, color cannot too dazzling, plant configuration should be soft, 
plant layout not too smart, to embody the quiet, elegant and not common style; General selection of palm foliage plants such as better. Can a light fair of asparagus decoration or reticulate grass and fruit such as taro green plants on the desk, to adjust the vision, alleviate fatigue; Can also be placed trailing vines plants on the bookshelf, from the top of the bookcase to float however, such as ivy, hanging bamboo plum, multiply the elegant atmosphere of the study. Need to pay special attention to is the adornment of the bookshelf green plant should be combined with books, antiques, forming a rich elegant atmosphere, give a person with enlightenment striving to make progress.

Area of the space of toilet is general not quite, it belongs to the interior space of humid, lighting sex is generally poor, so suits to choose some shade and hygrophilous plant, such as rattan pepper grass plant with low requirements for lighting, or kidney fern ; Toilet is tonal for light color fastens commonly, when selecting a plant color should be lively and advisable, and because of the special ecological toilet, sewage discharge of ammonia, hydrogen sulfide and other volatile substances emit some smell, and at the same time, the air pollution caused by the combined with poor ventilation of toilet, so it's best to choose herbs and other similar plants can absorb harmful gas. In addition, fake plants, dry flower is also a good selection of toilet greening. Can keep the original state, they tend to not only good vision, species diversity, people also do not need to spend effort to maintenance and management, this is don't want to do or don't have time to care for the people of afforest adornment, toilet is a very practical green choice.

Hotel in a place like this in general area is big, and height is high enough, has the characteristics of large spacious. The lobby of the hotel is the important place to display the corporate image, and can give a person leave deep impression, so now pay more and more attention to the lobby of the hotel interior design. Because there are too many people in the lobby and, is mainly used to welcome guests, so need to build a warm atmosphere to the lobby. To this, can put some air plants, such as poinsettia, other, Africa jasmine and so on; In the lobby of the office or rest area, can put some implication rich plant, such as the prosperous tower, etc. In addition, you can choose according to different locations in the lobby and put different plants, some moral good or beautiful plants can increase the lobby image sense of style, such as rich tree, araucaria, etc. In position such as stairs, guardrail, can decorate some vine plants, by climbing plants and vines drooping, increase indoor light, natural, lively atmosphere ${ }^{[5]}$.

Office is the modern people to work the main indoor environment, the design of modern office is becoming more and more human, in the modern office, usually for green design. In order to improve the staff's initiative and creativity, improve work efficiency, at the time of greening design of office, should create a positive atmosphere. To this, at the time of choosing plants for office, should be under the guidance of scientific, increase its diversity, both in its shape and color. Office space pervious to light quality, layout, size, and plants, plant type, color, and the way of configuration of both the employee's heart even physical different or even opposite effects ${ }^{[6]}$. Only in color, for example, research has shown that green foliage plants in the role of build relaxed and pleasant environment, white flower plants can inspire employees to calm and happy mood and alleviate the pressure of the employees, yellow flower plants and orange flower plants inspire employees calm and happy mood at the same time make the staff's work enthusiasm and improve work efficiency, therefore, in the office environment, recommend using the other as much as possible, and white hands, narcissus, small sunflower green foliage, white flowers, yellow or orange flowers plant ${ }^{[7]}$. Color is too bright flowers plant brings to the employees and happy at the same time also can make people nervous, scattered attention, reduce work efficiency, so the red gerbera and poinsettia and similar plants as far as possible need not in the office environment. In addition to the office area of different functional parts can also be used according to the nature of office put 
green plant, such as the President and chairman of the board of directors and other office can put kaffir lilythat has a positive meaning, in the finance department can put rich tree plants contain resources such as meaning, in the meeting room can put a few other good plants, cycads shadow resistance and so on.

\section{Conclusion}

Green plant landscape is the result of the nature, the application of green plants into the interior space design technique is more and more widely, and has already started to lead the direction of the development of interior design today. In be being designed indoors, through the reasonable application of green plant, show its unique shape and color, and then constructs the contains natural flavor of elegant indoor environment, make people more close to nature, blend in nature. In the quickening pace of life today, natural, quiet and comfortable indoor environment can help people reduce stress, relieve fatigue, make people's quality of life to the next level.

\section{Funds project:}

Key Laboratory of Wood Industry and Furniture Engineering of Sichuan Provincial Colleges and Universities.

\section{References}

[1] Zhou Yanmian ShaYushi. Residential complex space research [J]. Journal of construction, 2003, (3) : 3637.

[2] Shang Xiaomin. Natural landscape in the interior space to create [J]. Journal of Shanghai agronomy journal, 1999 (2) : 90-97.

[3] jian-bo zhou. Think about the whole building green residential environment [J]. J YuZhou university journal, 2001, 1 (18) : 63-67.

[4]. Xuhuifeng, Jinyanming, Yu Guoying, etc. Within the afforest adornment [M]. Beijing: China forestry publishing house, 2002:51-52.

[5]. Yuxiaoming. The application of ornamental plants in interior design [J]. Modern gardening, 2016, (9) : 145-146.

[6]. PanWen. Theory of greening application in indoor environment [D]. Northeast: the northeast normal university, 2014.

[7]. LiXia. Garden plant color to people's physical and mental influence [D]. Beijing forestry university, 2012 (6) : 199. 